\title{
Alkaline Phosphatase Increased, CTCAE
}

National Cancer Institute

\section{Source}

National Cancer Institute. Alkaline Phosphatase Increased, CTCAE. NCI Thesaurus. Code C143269.

A finding based on laboratory test results that indicate an increase in the level of alkaline phosphatase in a blood specimen. 